\title{
RE: RE: Role of rapid diagnostics for viral respiratory infections in antibiotic prescribing decision in the emergency department, by Li et al (2019)
}

\author{
Jing Li MA ${ }^{1}$, S. Lena Kang-Birken PharmD, FCCP2,3, Catelynn Kenner MPH ${ }^{1}$ and Lynn Fitzgibbons MD 4 \\ ${ }^{1}$ Cottage Health Research Institute, Santa Barbara Cottage Hospital, Santa Barbara, California, ${ }^{2}$ Department of Pharmacy Practice, Santa Barbara Cottage \\ Hospital, Santa Barbara, California, ${ }^{3}$ Thomas J. Long School of Pharmacy and Health Sciences, University of the Pacific, Stockton, California and ${ }^{4}$ Department of \\ Medical Education, Santa Barbara Cottage Hospital, Santa Barbara, California
}

To the Editor-We acknowledge the Letter to the Editor submitted by Rankin et $\mathrm{al}^{1}$ and appreciate its unique perspective. We thank Rankin et al for their feedback and emphasis on methodological integrity when making causal inferences.

In the original paper, the intention was to explore and describe associative or correlational factors of a physician's decision to prescribe antibiotics with a viral respiratory infection confirmed by PCR. ${ }^{2}$ A "table 2 fallacy" occurs when causal modeling is intended but does not account for confounding variables appropriately in the model, ${ }^{3}$ which does not apply to our study since our study was purely descriptive, with the limitations acknowledged. ${ }^{2}$ We thank Rankin et al again for the comments, and we suggest additional research in the future to investigate causation.

\section{Acknowledgments.}

Financial support. No financial support was received for the work presented in this letter.

Conflict of interest. The authors declare that they have no conflict of interest relevant to this article.

\section{References}

1. Rankin DA, Rebeiro PF, Haddadin Z, Halasa NB, Greevy RA. RE: Role of rapid diagnostics for viral respiratory infections in antibiotic prescribing decision in the emergency department, by Li et al (2019). Infect Control Hosp Epidemiol 2020;41:991-992.

2. Li J, Kang-Birken SL, Mathews SK, Kenner CE, Fitzgibbons LN. Role of rapid diagnostics for viral respiratory infections in antibiotic prescribing decision in the emergency department. Infect Control Hosp Epidemiol 2019;40:974-978.

3. Westreich D, Greenland S. The table 2 fallacy: presenting and interpreting confounder and modifier coefficients. Am J Epidemiol 2013;177:292-298.
Author for correspondence: S. Lena Kang-Birne, E-mail: lkang@sbch.org

Cite this article: Li J, et al. (2021). RE: RE: Role of rapid diagnostics for viral respiratory infections in antibiotic prescribing decision in the emergency department, by $\mathrm{Li}$ et al (2019). Infection Control \& Hospital Epidemiology, 42: 1523, https://doi.org/10.1017/ ice. 2020.388 